\title{
Uma análise materialista-histórica da juventude da classe trabalhadora brasileira
}

\begin{abstract}
Resumo:
O presente artigo objetiva promover a reflexão a respeito da realidade material da juventude da classe trabalhadora no Brasil, um país de capitalismo periférico e dependente, onde desde muito cedo, jovens experimentam a dualidade trabalhar $x$ estudar. Por esse motivo tornam-se potenciais alunos dos cursos de Educação de Jovens e Adultos (EJA), e com isso, vivenciam políticas de educação em modelos aligeirados e fragmentados, além de, negação do direito aos espaços e equipamentos de lazer e cultura. Como suporte teórico-metodológico valemo-nos de autores e autoras baseados na perspectiva materialista histórica dialética e da análise de dados abertos do IBGE. Como delimitação histórica abarcamos o período a partir do golpe parlamentar de 2016, que resultou no impeachment da então presidenta Dilma. Compreendemos haver uma perversa valorização de uma política penal de encarceramento e de extermínio da população jovem trabalhadora oriunda das periferias, que "refratam e refletem" as reformas sociais, trabalhistas e educacionais, além do desmantelamento de estruturas institucionais promovedoras de políticas para juventude, implementadas a partir de 2016. Ao final, concluímos que o Estado brasileiro na conjuntura atual não promove políticas de inclusão ao mundo do trabalho, à cultura e à educação, em especial, emancipadora, para os jovens da classe trabalhadora.
\end{abstract}

\section{Palavras-chave:}

Juventude. Classe Trabalhadora. EJA. Exploração.

\section{A materialist-historical analysis of the youth of the Brazilian working class}

\begin{abstract}
This article aims to promote reflection on the material reality of working-class youth in Brazil, a country of peripheral and dependent capitalism, where young people experience the duality of working $x$ studying from an early age. For this reason, they become potential students of Youth and Adult Education (EJA) courses, and with that, they experience education policies in light and fragmented models, in addition to denial of the right to leisure and cultural spaces and equipment. As theoretical and methodological support, we use authors based on the dialectical historical materialist perspective and the analysis of open data from IBGE. As a historical delimitation we cover the period from the 2016 parliamentary
\end{abstract}


coup, which resulted in the impeachment of the then president Dilma. We understand that there is a perverse valorization of a penal policy of incarceration and extermination of the young working population from the peripheries, which "refract and reflect" social, labor and educational reforms, in addition to the dismantling of institutional structures that promote youth policies, implemented at from 2016. At the end, we conclude that the Brazilian State in the current situation does not promote policies of inclusion to the world of work, culture and education, in particular, emancipatory, for young people of the working class.

Keywords: Youth. Working class. EJA. Exploration.

\section{Un análisis histórico-materialista de la juventud de la clase trabajadora brasileña}

Resumen: Este artículo tiene como objetivo promover la reflexión sobre la realidad material de la juventud obrera en Brasil, un país de capitalismo periférico y dependiente, donde los jóvenes experimentan la dualidad de trabajar x estudiar desde una edad temprana. Por ello, se convierten en potenciales alumnos de los cursos de Educación de Jóvenes y Adultos (EJA), y con ello viven las políticas educativas en modelos ligeros y fragmentados, además de la negación del derecho al esparcimiento y espacios y equipamientos culturales. Como soporte teórico y metodológico utilizamos autores basados en la perspectiva materialista histórica dialéctica y el análisis de datos abiertos del IBGE. Como delimitación histórica cubrimos el período desde el golpe parlamentario de 2016, que resultó en el juicio político de la entonces presidenta Dilma. Entendemos que existe una valorización perversa de una política penal de encarcelamiento y exterminio de la población trabajadora joven de las periferias, que "refractan y reflejan" reformas sociales, laborales y educativas, además del desmantelamiento de estructuras institucionales que promueven políticas de juventud, implementadas de 2016. Al final, concluimos que el Estado brasileño en la situación actual no promueve políticas de inclusión al mundo del trabajo, la cultura y la educación, en particular, emancipadoras, para los jóvenes de clase trabajadora.

Palabras clave: Juventud. Clase obrera. EJA. Exploración.

\section{Introdução}

Este artigo busca analisar a realidade na qual se insere a grande massa de jovens brasileiros e brasileiras que vivenciam a materialidade histórica da dualidade entre estudar e trabalhar. A partir do século XIX, em especial do séc. XX, a categoria “juventude(s)" vem ganhando destaque nos estudos de educação e sociologia, sobretudo a partir de um novo campo de abordagem a "sociologia da juventude", abarcando diversas perspectivas teóricas-metodológicas de análise.

Abordamos aqui a juventude da classe trabalhadora brasileira, atentando para um contexto de inserção em uma economia mundializada, cujo dinamismo consiste em tornar, cada vez mais, o país refém de um capitalismo periférico e dependente (FERNANDES, 1975). Com isso,

Utilizamos juventude como categoria sociológica, construída social e historicamente. Alguns pesquisadores afirmam que devemos tratar de juventudes e não de juventude; entretanto, fizemos a opção teórica e política por utilizarmos apenas a palavra no singular, pois a pesquisa objetiva tratar não de uma juventude genérica e abstrata, mas de uma juventude real e concreta: a juventude da classe trabalhadora brasileira da atualidade. Entendemos ainda que tratar da juventude da classe trabalhadora da atualidade não significa que a tomamos como única e uniforme, ao contrário, há diversidade dentro do segmento juvenil da classe trabalhadora, inclusive pelo crescente processo de heterogeneização da classe trabalhadora contemporânea (gênero, étnico-racial, ocupação espacial das cidades, renda e outros). (LANES, 2019, p. 393). 
Entendemos que esses sujeitos estão permanentemente na condição de potenciais trabalhadores. Ao ainda muito precocemente vivenciarem essa realidade acabam por concorrer na dinâmica trabalhar e/ou estudar. Com isso tornam-se potenciais alunos dos cursos de Educação de Jovens e Adultos (EJA), modalidade da educação básica que de acordo com a Lei de Diretrizes e Base da Educação Nacional no 9.394/1996 (LDB 9394/96) é destinada "àqueles que não tiveram acesso ou continuidade de estudos no ensino fundamental e médio na idade própria e constituirá instrumento para a educação e a aprendizagem ao longo da vida" (BRASIL, 1996).

Através de observação da realidade cotidiana dessa juventude, percebemos as trincheiras de luta que a aflige. Políticas precárias de educação, escolarização fragmentada, negação do direito aos espaços e equipamentos de lazer e cultura, alto índice de desemprego, grande demanda de ocupações precarizadas, em especial através do processo de uberização do trabalho, maior quantitativo da população carcerária e da assassinada etc.

Diante desse quadro, fazemos as seguintes perguntas: qual a realidade educacional e socioeconômica da juventude brasileira após 2016? Quais políticas vêm sendo adotadas pelo Estado brasileiro a fim de abarcar a população jovem trabalhadora, garantindo seus direitos sociais e à educação?

Como suporte para responder esses questionamentos tomaremos como aporte metodológico dados abertos expressos nas Pesquisas Nacionais por Amostra de Domicílios Contínuas (PNAD-C) do Instituto Brasileiro de Geografia e Estatística (IBGE).

\section{Breve contextualização do Brasil pós 2016}

A partir da nova crise estrutural do capital, uma série marcada por governos de caráter progressistas foi encerrada, não havendo mais espaço para um programa de governo conciliador de classes, como foram os liderados pelo Partido dos Trabalhadores (PT) através de Lula (2003-2010) e Dilma (2011-2016). Com isso, estrutura-se um golpe disfarçado em um processo de impeachment da então presidenta Dilma Rousseff, que teve início em 2015 e se efetivou em 2016, resultando na sua perda de mandato e na consequente assunção do então vice-presidente Michel Temer. Um processo que se deu a partir da articulação entre o parlamento, a mídia televisiva, o judiciário, as forças armadas e fração da burguesia nacional.

Em relação a isto, podemos entender que a votação do impedimento na Câmara Federal, midiatizado à grande massa pela internet e pelos principais canais de televisão, como uma vergonha do ponto de vista institucional e moral. Um acontecimento que, de certo modo, vem corroborando para o aumento de uma série de ações violentas, tendo em vista o emprego de narrativas construídas em torno de jargões excludentes fomentadores de ódio, sobretudo através do fundamentalismo religioso: "família tradicional brasileira", "cidadão de bem", "bandido bom é bandido morto", culto à ditadores militares assassinos, pedidos de um novo regime político nos moldes da ditadura empresarial-militar e o extermínio de cidadãos e cidadãs que possuem ideologias políticas de esquerda.

\footnotetext{
Para que possamos conhecer a natureza essencial do golpe de Estado ocorrido no Brasil em 2016 temos que levar em consideração não apenas a processualidade imediata da conjuntura política nacional, com os bastidores do jogo de poder entre PT, PMDB e PSDB e as articulações sinistras entre Congresso Nacional, Supremo Tribunal Federal, Procuradoria Geral da República, Ministério Público Federal e Polícia Federal no seio do aparelho de Estado, ao lado da Operação Lava-Jato e a intensa manipulação da opinião pública pela grande imprensa, com destaque para a TV Globo. (ALVES, 2016).
}

Logo após o impeachment, Temer dá início a um projeto de reformas, em ritmo acelerado, da qual a crise do capital neoliberal necessitava para se reestruturar. Iniciou pela Proposta de Emenda Constitucional no 55 em 2016 (BRASIL, 2016), que foi aprovada e passou a limitar os gastos públicos por 20 anos, congelando a ampliação de investimentos em pastas sociais como educação e saúde. 
No ano seguinte, a aprovação da Lei da Terceirização, no 13.429 de março de 2017 (BRASIL, 2017b), representa a continuidade de seu projeto. Assim, o marco legal abre caminhos para elevar a precarização da força de trabalho, uma vez que autoriza a contratação de terceirizados para exercer qualquer função nas empresas, rompendo com o texto anterior que autorizava apenas serviços que não tivessem relação direta com a atividade essencial da empresa.

Neste mesmo ano, o governo conseguiu aprovar a Reforma do Ensino Médio, inicialmente estruturada através de Medida Provisória (MP) no 748/2016 e posteriormente sancionada pela Lei no 13.415/2017 (BRASIL, 2017a).

Segundo Motta e Frigotto (2017, p. 357), a reforma do Ensino Médio retrata

[...] a insanável contradição ético-política do pensamento e da moral capitalista do tipo dependente: perversamente autoritário. Imbuída do caráter ideológico instrumental, esta é conduzida como processo natural de modernização - fetichizada pelo determinismo tecnológico-inovador -, despida de relações de poder e sem historicidade. Ou seja, a história de luta voltada para a supressão do dualismo estrutural do Ensino Médio foi rasgada; não há sujeitos históricos, e sim alunos abstratos, jovens trabalhadores deslocados de suas condições objetivas e materiais reais.

Essa reforma que surge com a propaganda de um maior protagonismo juvenil, tende a condenar os filhos e filhas da classe trabalhadora à uma educação mais aligeirada, voltada aos trabalhos simples, reduzindo consideravelmente os conhecimentos críticos-reflexivos em seus currículos. Em virtude disso, a atenção acaba se voltando para as questões técnicas - relacionadas à preparação para o mercado de trabalho -, deixando de lado uma perspectiva de uma educação que estimule o desempenho de atividades complexas, a conquista de autonomia para lutar por seus direitos e o prosseguimento dos estudos em nível superior.

Cabe ressaltar que o Ensino Médio (EM) da modalidade EJA também deverá se enquadrar à reforma, segundo o Art. 5o da atualização das Diretrizes Curriculares para o Ensino Médio:

O ensino médio em todas as suas modalidades de ensino e assuas formas de organização e oferta, além dos princípios gerais estabelecidos para a educação nacional no art. 206 da Constituição Federal e no art. 3 da LDB, será orientado pelos seguintes princípios. (BRASIL, 2018).

A partir desta análise, entendemos que a legislação vai totalmente na contramão de uma educação voltada para as especificações dos trabalhadores e trabalhadoras, para uma concepção de formação crítica. Um exemplo disso é a possibilidade de os sistemas educativos oferecerem na EJA/ EM “até $80 \%$ (oitenta por cento) de sua carga horária a distância, tanto na formação geral básica quanto nos itinerários formativos do currículo [...]" (BRASIL, 2018). Sabemos que tal proposição reduz gastos e não contempla grande parte dos sujeitos que são excluídos do acesso à internet $\mathrm{e}$ desprovidos de equipamentos que deem condições de acompanhar as atividades. Além disso, corre o risco dessa possibilidade virar regra, aumentando os índices de exclusão desses sujeitos.

Contraditoriamente, "nos curtos momentos de expansão do capital brasileiro a força de trabalho demandada foi para o trabalho simples" (FRIGOTTO; MOTTA, 2017, p. 358) e, diante disso, podemos perceber que tal lógica se perpetua, visto que o número de trabalhadores precarizados, que labutam na informalidade através dos aplicativos de plataforma digital e de pequenos empreendimentos informais, vem crescendo a cada ano.

Mostra-se assim um projeto demandado pelo mercado, que chega às escolas de fora para dentro e que visa uma formação alicerçada em bases demarcadas pelo empreendedorismo, buscando fomentar a ideologia hegemônica de "seja seu próprio patrão", ou, "seja um empreendedor". Tal projeto acaba eximindo dos empresários qualquer responsabilidade trabalhista e social, o que impacta diretamente na produção de mais valor. 
Afinal, o país não vem gerando emprego, em especial, formal, para esses jovens e adultos, resultando em um massivo "exército industrial de reserva", restando apenas a ocupação nessas tarefas desprendidas de uma qualificação mais aprimorada. Neste contexto o governo age dissimulando ofertar o ensino médio com possibilidades de qualificação profissional para um pleno emprego, o que é fictício. E por conseguinte, inviabiliza a possibilidade de uma ascensão desses estudantes à universidade devido a essa formação aligeirada.

Concordamos com as perspectivas de Motta e Frigotto (2017), que entendem que o avanço tecnológico e a formação qualificada de trabalhadores exigem romper com a posição de subordinação e dependência do país, na divisão internacional do trabalho.

Para os gestores governamentais, a atualização do currículo desta etapa da educação básica busca retirar disciplinas "desinteressantes", que os jovens têm pouca atração e que acaba influenciando na grande "evasão" escolar. Motta e Frigotto (2017) nos mostram que essa ação em propor uma reforma é oriunda de instituições que expressam políticas de países centrais para os países dependentes.

A melhoria do ensino, tendo como referencial os critérios de qualidade definidos pela Organização de Cooperação para o Desenvolvimento Econômico (OCDE), por meio do Programa Internacional de Avaliação de Estudantes (PISA), e os sistemas de avaliação nacional e estaduais, tais como o Índice de Desenvolvimento da educação (IDEB), baseados nos mesmos critérios: português, matemática e, recentemente ciências; e a modernização do Ensino Médio, no sentido de flexibilizar o currículo por áreas de conhecimento, voltando-se para aptidões dos alunos e das unidades escolares. (MOTTA; FRIGOTTO, 2017, p. 361).

Sendo assim, entendemos que o papel político dos organismos internacionais nas políticas educacionais do país, se dá através dos mecanismos de avaliação em larga escala e do desenvolvimento de habilidades e competências para entrada no mundo do trabalho, formal ou informal; neste último caso tomando maior destaque na contemporaneidade o ensino de empreendedorismo. Com isso, as ações por eles propostas prezam, em sua concretude, por uma produção baseada na superexploração, acarretando o aumento demais valor.

Quanto à reforma realizada em 2017, através do artigo 36, institui que o currículo no Ensino Médio será composto pela Base Nacional Comum Curricular (BNCC) e por itinerários formativos "que deverão ser organizados por meio da oferta de diferentes arranjos curriculares, conforme a relevância para o contexto local e a possibilidade dos sistemas de ensino" (BRASIL, 2017).

Assim temos uma formação geral básica, contemplada pela BNCC, em quatro áreas de conhecimentos: Linguagens e suas Tecnologias, Matemática e suas Tecnologias, Ciências da Natureza e suas Tecnologias e Ciências Humanas e suas Tecnologias. No que concerne aos Itinerários Formativos, são apresentados aos educandos como opções que poderão escolher o seu percurso educativo. Teoricamente, será facultado ao educando essa escolha, mas essa possibilidade funcionará ao molde de uma liberdade tutelada, pois será de acordo com o que for oferecido em sua escola ou, sendo otimista, em sua região.

Com relação à BNCC, Marsiglia et al. (2017, p. 118) nos traz a seguinte crítica:

Ao enfatizar as 'habilidades', as 'competências', os 'procedimentos' e a 'formação de atitudes', e não destacar os conteúdos escolares, o trabalho educativo e o ensinar, o documento traz uma perspectiva que visa adaptar os alunos ao mercado de trabalho ou, mais propriamente, ao 'empreendedorismo'. Ou seja, com o crescente desemprego e a consequente diminuição do trabalho formal, o objetivo dessa formação é preparar os filhos da classe trabalhadora para o mundo do trabalho informal e precarizado, compatível com as novas demandas do capital para este século, voltadas para a acumulação 'flexível'. 
Somando-se a essas ações, Temer encerra a série de reformas através da Reforma Trabalhista, aprovada em julho de 2017. Essa foi mais uma das ações que expropriou grandes direitos dos trabalhadores, sob alegação de que tornaria as relações de trabalho mais "flexíveis" e diminuiria o desemprego, o que não aconteceu, passados quase quatro anos desde a sua aprovação e sanção. Em breve análise, depreende-se que a reforma em questão legitimou acordos acertados entre empregado e empregador - como se ambos tivessem o mesmo poder de barganha. Ela possibilitou, ainda, o trabalho remoto e o trabalho intermitente, dando a empresa o poder de contratar um "colaborador" para realizar trabalhos esporádicos, de acordo com a sua demanda e sem responsabilidades empregatícias como férias, 13ㅇsalário etc. Dentre outros aspectos, teve um papel central na desmobilização dos sindicatos, desautorizando a contribuição sindical obrigatória.

Nota-se que mesmo com uma impopularidade recorde, Michel Temer conseguiu realizar todas essas reformas, sendo o presidente mais impopular desde a redemocratização, com avaliação considerada péssima ou ruim de $74 \%$. Isso demonstra a coalização de forças montada para sua governabilidade.

Com o advento do processo eleitoral de 2018 e a assunção de Jair Bolsonaro continua-se a saga de reforma neoliberal. Agora comandada por Paulo Guedes (Ministro da Economia), que tem como ideal as reformas neoliberais implementadas no Chile, este governo passa a operar aparelhando todas as instituições e agindo, segundo Mbembe (2018, p. 5), através de uma necropolítica efetuada pelo Estado, instituindo "o poder e a capacidade de ditar quem pode viver e quem deve morrer".

Mesmo com precária articulação política na Câmara Federal o governo conseguiu aprovar a mais aguardada das reformas - a Reforma da Previdência. Isso demonstra o quanto a burguesia nacional detém o poder e interfere nas decisões políticas do Estado brasileiro. Esta reforma determinou condicionantes que na prática excluem a possibilidade de inúmeros trabalhadores e trabalhadoras, especialmente os mais vulneráveis, de se aposentarem. Além disso, ela dizima direitos anteriormente garantidos pela Seguridade Social. Ademais, o governo de Jair pretende aprovar as reformas tributária e administrativa. Contudo, virtude a conjuntura da pandemia do coronavírus instalada em 2020 ainda não foi possível.

No tocante as políticas de Educação, observamos um total desapreço do governo por uma educação pública laica e de qualidade, ao contrário, o que o governo vem fazendo é um ataque constante aos professores e professoras, desvalorizando o trabalho docente com um discurso populista ideológico. Um dos setores mais atacados foram as universidades públicas, onde se buscou até mesmo marginalizá-las.

$\mathrm{Na}$ esfera da Educação de Jovens e Adultos temos uma sequência de ações que iniciaram ainda no governo Temer e se agravaram agora no governo Bolsonaro. Temer extinguiu os recursos do programa Brasil Alfabetizado e desestruturou a Secretaria de Educação Continuada, Alfabetização, Diversidade e Inclusão (SECADI). Através do Decreto no 9.759/19 (BRASIL, 2019), Bolsonaro, extinguiu a SECADI e a CNAEJA (Comissão Nacional e Alfabetização de Educação de Jovens e Adultos). Com isso a estrutura do Ministério da Educação findou todos os setores responsáveis diretamente pelas políticas de EJA.

A fim de uma melhor compreensão acerca da EJA, tomando como referência o contexto histórico-político, dialogamos com a formulação proposta por Alvarenga (2016, p. 123), por meio da qual ela afirma que

No Brasil, as iniciativas que envolvem a Educação de Jovens e Adultos merecem ser analisadas pela inter-relação entre os processos econômico, político e social, no ordenamento das políticas públicas quando se tem como objetivo de análise as ações governamentais para este setor, considerados os contextos históricos-políticos nos quais estão sendo formulados.

Essa conjuntura material agravou a realidade dos jovens filhos e filhas da classe trabalhadora, sendo potencializada com o advento da crise sanitária da pandemia da covid-19. No tópico a seguir analisaremos os dados relativos a essa realidade. 


\section{A realidade concreta da juventude trabalhadora}

A classe trabalhadora vem vivenciando desde o segundo mandato do governo Dilma (2014) uma realidade complexa de falta de ocupação laboral. O número de pessoas desocupadas vem se mantendo, desde o golpe parlamentar de 2016, acima de 14 milhões de pessoas. Podemos observar essa realidade através do Gráfico 1.

Assim, compreendendo a importância de problematizar esta realidade, ilustramos dois gráficos. No primeiro apresentamos índices de pessoas desocupadas, e, no segundo, voltamos o nosso olhar para a realidade vivenciada pela população jovem ${ }^{1}$, especialmente no que se refere à desocupação.

Gráfico 1 - Série histórica nacional de pessoas desocupadas

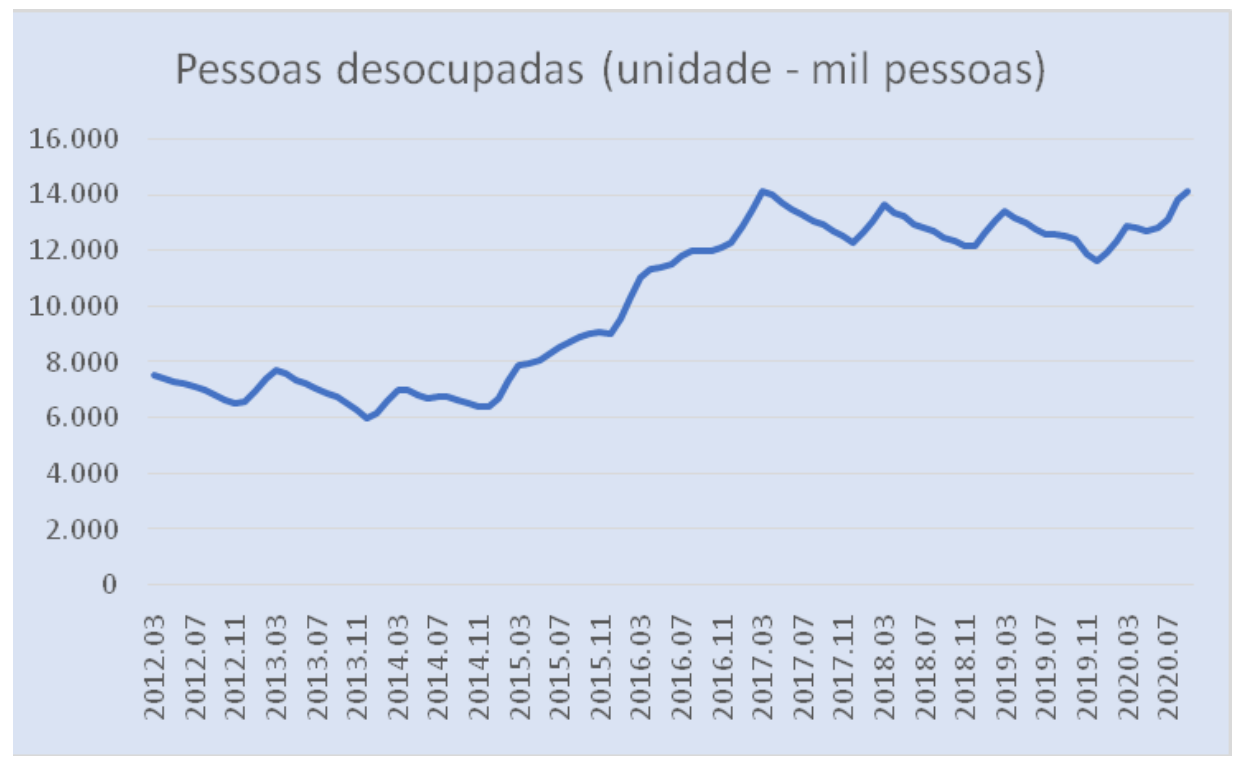

Fonte: PNAD Contínua/IBGE (2020).

Gráfico 2 - Série histórica nacional de pessoas desocupadas por Idade

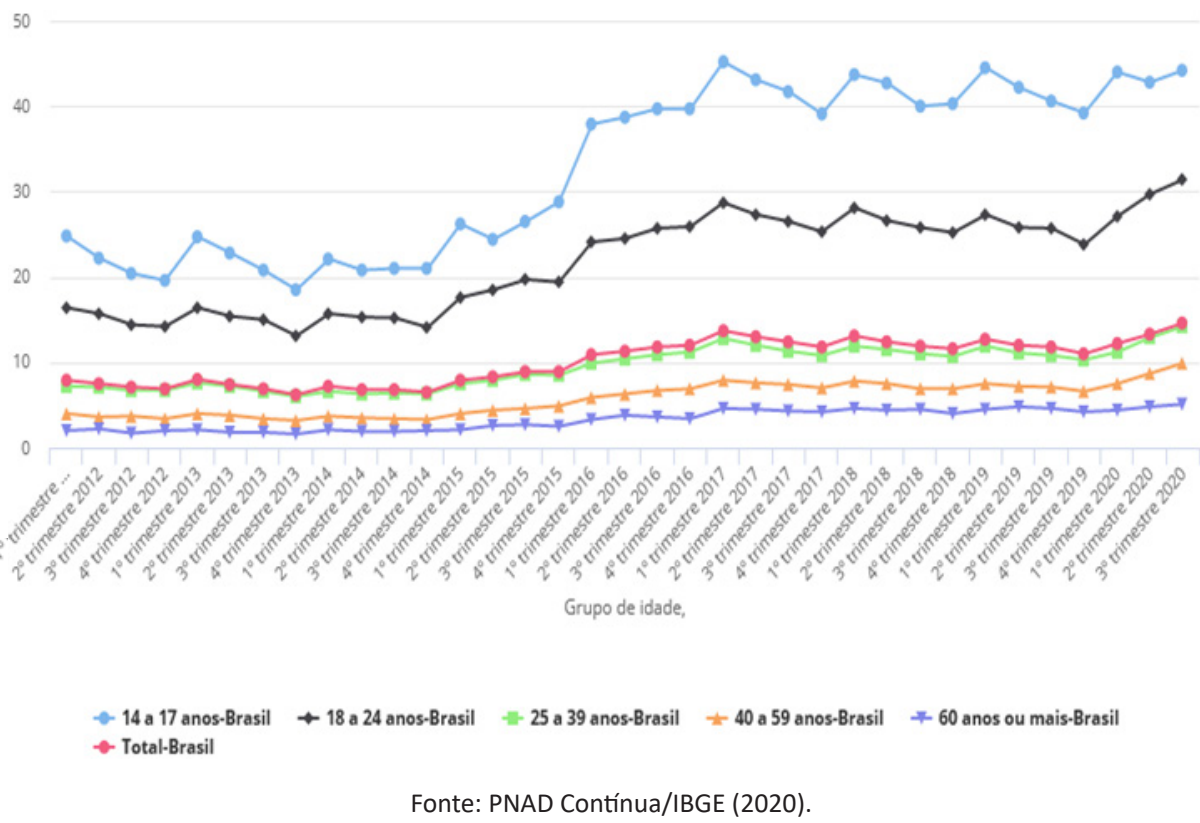

1 Utilizamos a definição de juventude do Estatuto da Juventude de 2013, que considera a faixa etária de 15 a 29 anos (BRASIL, 2013 ). 
O IBGE considera como desocupadas as pessoas sem trabalho e que tomaram alguma providência efetiva para consegui-lo no período de referência de 30 dias, e que estavam disponíveis para assumi-lo. Ao considerar os desalentados, ou seja, aqueles que perderam a esperança ou não possuem mais condição de buscar um emprego, essa realidade se torna ainda mais trágica.

No que se refere ao grau de instrução temos uma realidade ainda muito ingrata. A taxa de analfabetismo pouco reduziu de 2016 até 2019. Para as pessoas com 15 anos ou mais temos os seguintes percentuais: 7,2\% (2017), 6,8\% (2018) e 6,6\% (2019); e para os com idade a partir de 60 anos: $24,4 \%$ (2016), $18,6 \%$ (2018) e $18 \%$ (2019).

Já o percentual de pessoas a partir de 25 anos que concluíram o percurso da educação básica, ou seja, finalizaram o ensino médio, corresponde a apenas $48,6 \%$ da população. Uma materialidade que nos mostra que o país ainda não conseguiu universalizar por completo a educação básica para todos. Mais da metade da população de 25 anos ou mais são potenciais alunos da Educação de Jovens e Adultos, a mesma que o governo extinguiu recursos e desmantelou a base política institucional.

Esses dados nos mostram que a etapa do Ensino Médio continua a ser um "gargalo" para a juventude trabalhadora, pois o ensino fundamental encontra-se com percentual de $99 \%$ de taxa de escolarização para as pessoas de 6 a 14 anos.

Para sintetizar melhor a realidade escolar da população jovem brasileira e seu impacto em uma ocupação, temos o quadro abaixo.

\section{Quadro 1 - Jovens por condição de estudo e situação na ocupação em 2019}

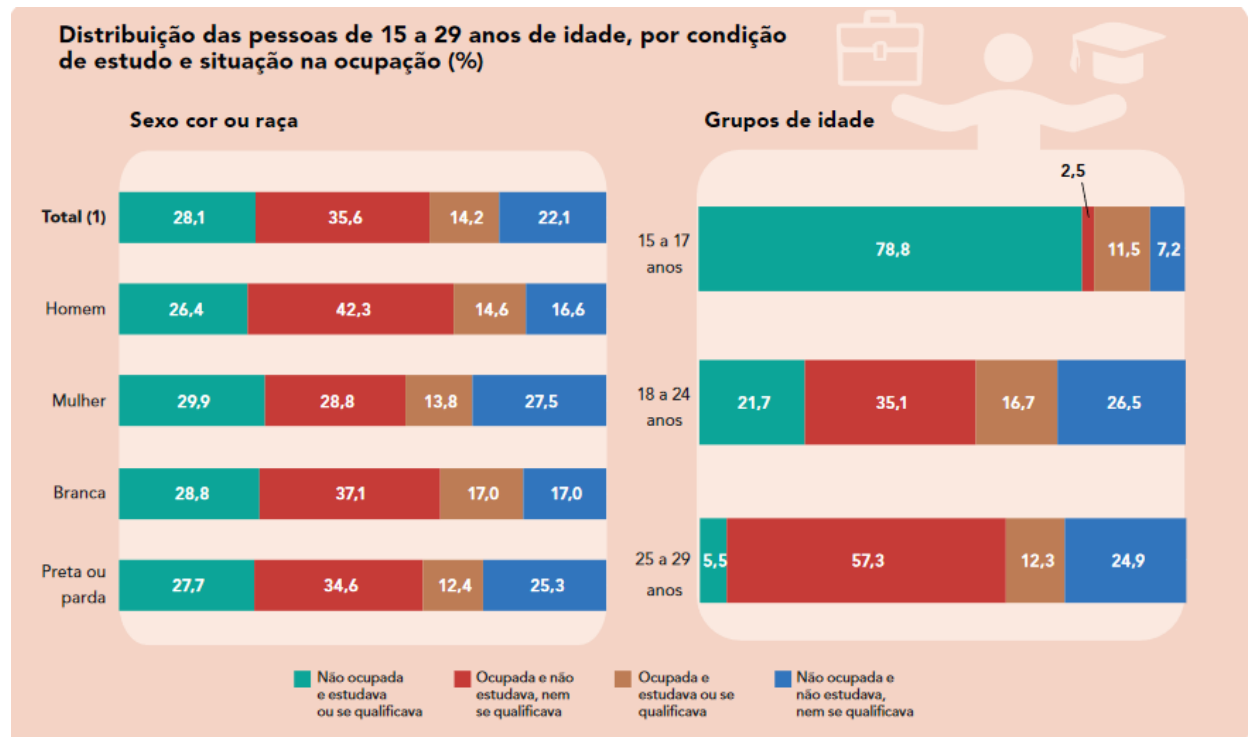

Fonte: PNAD Contínua/IBGE (2020).

O quadro acima mostra que uma parcela significativa dos jovens - $14,2 \%$ - estudavam e trabalhavam e que um percentual um pouco mais expressivo - 22,1\% - não estudava e nem estava ocupado. Isso reflete uma realidade complexa da juventude brasileira, pois para os que possuem essa dupla jornada

[...] não quer dizer que eles produzem maior quantidade de mais-valor por estarem nessa dupla condição, mas significa que para eles a jornada de trabalho continua, mesmo que não estejam diretamente produzindo mais-valia. Esse dado aliado ao aumento da intensificação do trabalho e da ampliação da jornada de trabalho, próprios da superexploração do trabalho nas economias periféricas, evidencia o quanto a sociabilidade capitalista periférica é brutal com a juventude latino-americana, que se vê obrigada a se submeter às consequências da superexploração da força de trabalho e buscar, simultaneamente, a continuidade de sua formação profissional com vistas a manter-se na condição de superexplorado. (LANES, 2019, p. 403). 
Com relação aos jovens que não estão trabalhando e nem estudando, podemos entender que muitos encontram-se numa situação de exclusão desses espaços. Uma exclusão proporcionada pelo próprio sistema capitalista, que visa formar um "exército industrial de reserva" como estratégia de submissão da superexploração.

Vivenciando essa realidade de falta de oportunidades e de uma perspectiva positiva de presente e futuro, muitos desses jovens acabam sendo absorvidos não por uma política pública de inserção social, mas sim por uma política de repressão do Estado, baseada no encarceramento da população juvenil periférica. De acordo com dados do levantamento de Informações Penitenciárias (Infopen), em 2016 do universo total de pessoas encarceradas no país, 55\% são jovens de 18 a 29 anos (VERDÉLIO, 2017). Cabe ressaltar a realidade do Brasil como sendo o terceiro país com maior população presa.

Com relação a população assassinada do país, a juventude também se sobressai, segundo o Atlas da Violência, em 2018, jovens de 15 a 29 anos representaram 53,3\% do total de homicídios, sendo $75,5 \%$ do total das vítimas negras (KADANUS, 2020).

Assim, entendemos que há um imbricamento entre a política social e a política penal, atendendo aos interesses da financeirização do capital: de um lado programas focalizados, fragmentados; e de outro a ampliação e consolidação de uma rede policial-penal. As duas estratégias são parte de um único dispositivo que tem por finalidade a gestão e o controle social dos pobres, de modo a retificar comportamentos das populações recalcitrantes, assegurando o expurgo cívico dessa população considerada incorrigível (WACQUANT, 2003) e, sobretudo, buscando manter os padrões de acumulação do capital nas economias dependentes. (LANES, 2019, p. 408).

Com isso, entendemos a intencionalidade dos grupos dirigentes do capital em propor políticas institucionais que visam a manutenção de seus padrões de acumulação. Políticas que se articulam nas esferas social, educacional, penal, cultural entre outras.

\section{Considerações finais}

Verificamos através da materialidade concreta expressa pelos dados, uma realidade perversa de valorização de uma política penal de encarceramento e de extermínio da população jovem trabalhadora das periferias, em especial negra, evidenciando um racismo institucional e estrutural existente no país.

Essa realidade se mostra fruto de políticas de governo que vêm sendo implementadas historicamente, em especial a partir de 2016, e que impactam a vida da juventude trabalhadora negativamente.

Não podemos dissociar as ações tomadas pelo Estado das demandas impostas pelos organismos do capitalismo central, pois "em síntese, as economias dependentes foram transformadas em mercadoria, negociáveis a distância, sob condições seguras e ultra-lucrativas” (FERNANDES, 1975, p. 17).

Tais ações se refletem em políticas públicas sociais, econômicas e educacionais, expropriando direitos e condições de uma ascensão social. Com isto, elas revelam-se negadoras de direitos constitucionais como educação para todos independentemente da idade. E não por aí, uma vez que buscam agir de modo a manter sua hegemonia e para isso capturam algumas ideias utilizadas pelo campo progressista como "protagonismo juvenil" e associam-na a conceitos gerencialistas como "empreendedorismo". Para tanto, contam com apoio dessas instituições como Banco Mundial e Organização das Nações Unidas para Educação, Ciência e Cultura (Unesco) que, não por acaso, elogiaram muito as reformas implementadas pelo Estado nestes últimos anos.

Conforme destacamos no decorrer deste estudo, essas ações deliberam uma realidade que atinge em maior proporção os jovens, enquadrando-os em percentuais consideráveis em aspectos 
como: maior população precarizada, desocupada, desalentada, encarcerada, assassinada e com acesso fragmentado a políticas sociais e de educação. Isso corrobora com a formulação de Marx (2014, p. 64), por meio da qual ele afirma que “[...] não faltarão aos senhores capitalistas carne e sangue frescos para serem explorados e aos mortos será determinado que enterrem os seus mortos".

Contudo, embora vivenciemos um período histórico de desmantelamento total de conquistas históricas da classe trabalhadora e de avanço de um governo de características protofascistas, enquanto engajados políticos devemos buscar mecanismos que surjam nas brechas das contradições do sistema capitalista. Deste modo,

Se, por um lado, o pessimismo da razão não permite elidir, na análise, o quadro delineado neste trabalho, por outro, as contradições inerentes a todos os fatos sociais e o otimismo da vontade nos obrigam a trazer, ainda que brevemente, as formas como a resistência da classe trabalhadora, embora cada vez mais pulverizada, se fazem presentes nos embates político-ideológicos que marcam sua educação. Nesse sentido, não podemos ignorar que diferentes formas dessas resistências operam num cenário de correlações de forças que, embora bastante desfavorável, apontam para a construção de alternativas [...]. (RUMMERT; ALGEBAILE; VENTURA, 2013, p. 735-736).

Sendo assim, devemos protagonizar mecanismos que nos levem a uma resistência ativa de modo que possamos nos organizar e insurgir em meio aos tensionamentos resultantes das crises cíclicas do capital. Para isso, espaços de sociabilidade como escolas, movimentos sociais, sindicatos etc. são de grande potencial.

\section{Referências}

ALVARENGA, Marcia Soares de. A Educação de Jovens e Adultos no PNE 2014-2024: entre os ajustes econômicos e os direitos sociais na atual conjuntura de crises no Brasil. Educação e Cultura Contemporânea, Rio de Janeiro, v. 13, n. 33, p. 121-138, 2016. Disponível em: http://periódicos.estacio.br/index.php/reeduc/article/viewArticle/2434. Acesso em: 18 nov. 2020.

ALVES, Giovanni. O golpe de 2016 no contexto da crise do capitalismo neoliberal. Blog da Boitempo, São Paulo, 8 jun. 2016. Disponível em: https://blogdaboitempo.com.br. Acesso em: 22 dez. 2020.

BRASIL. Lei n. 9.394, de 20 de dezembro de 1996. Estabelece as diretrizes e bases da educação nacional. Brasília, DF: Presidência da República, [1996]. Disponível em: http://www.planalto.gov.br/ccivil_03/leis/19394.htm. Acesso em: 19 nov. 2020.

BRASIL. Lei $n .^{\circ}$ 12.852, de 5 de agosto de 2013. Institui o Estatuto da Juventude e dispõe sobre os direitos dos jovens, os princípios e diretrizes das políticas públicas de juventude e o Sistema Nacional de Juventude - SINAJUVE. Brasília, DF: Presidência da República, [2013].

BRASIL. Lei n. 13.415, de 16 de fevereiro de 2017. Conversão da Medida Provisória 746, de 2016. Brasília, DF: Presidência da República, [2017a]. Disponível em: https://bit.ly/2HrGicv. Acesso em: 10 dez. 2020.

BRASIL. Lei n. 13.429, de 31 de março de 2017. Altera dispositivos da Lei no 6.019, de 3 de janeiro de 1974 [...]. Brasília, DF: Presidência da República, [2017b].

BRASIL. Resolução CNE/CEB n. ${ }^{\circ}$ 3/2018, de 21 de novembro de 2018. Atualiza as Diretrizes Curriculares Nacionais para o Ensino Médio. Brasília, DF: Ministério da Educação, [2018]. Disponível em: http://novoensinomedio.mec.gov. br/resources/downloads/pdf/dcnem.pdf. Acesso em: 20 dez. 2020.

BRASIL. Decreto n. 9.759, de 11 de abril de 2019. Extingue e estabelece diretrizes, regras e limitações para colegiados da administração pública federal. Brasília, DF: Presidência da República, [2019]. 
BRASIL. Emenda Constitucional n. ${ }^{\circ}$ 95, de 15 de dezembro de 2016. Altera o Ato das Disposições Constitucionais Transitórias, para instituir o Novo Regime Fiscal, e dá outras providências. Brasília, DF: Senado Federal, [2016].

FERNANDES, Florestan. Capitalismo dependente e classes sociais na América Latina. 3. ed. Rio de Janeiro: Zahar, 1975.

KADANUS, Kelli. Estado por estado: onde os homicídios aumentaram e onde caíram. Gazeta do Povo, Brasília, DF, 27 ago. 2020. Disponível em: https://www.gazetadopovo.com.br/republica/homicidios-taxa-por-estado-atlas-da-violencia/. Acesso em: 23 dez. 2020.

LANES, Mônica Paulino de. Exército industrial de reserva e juventude no capitalismo dependente brasileiro na atualidade. Revista Praia Vermelha, Rio de Janeiro, v. 29, n. 1, p. 391-411, 2019. Disponível em: https://revistas.ufrj.br/index. php/praiavermelha/article/view/14240. Acesso em: 20 dez. 2020.

MARSIGLIA, Ana Carolina Galvão et al. A base nacional comum curricular: um novo episódio de esvaziamento da escola no Brasil. Germinal: Marxismo e Educação em Debate, Salvador, v. 9, n. 1, p. 107-121, abr. 2017.

MARX, Karl. Trabalho assalariado e capital e salário, preço e lucro. 2. ed. São Paulo: Expressão Popular, 2014.

MBEMBE, Achille. Necropolítica: biopoder, soberania, estado de exceção, política da morte. São Paulo: n-1 edições, 2018.

MOTTA, Vânia Cardoso da; FRIGOTTO, Gaudêncio. Por que a urgência da reforma do ensino médio? Medida Provisória no 746/2016 (Lei no 13415/2017). Educação \& Sociedade, Campinas, v. 38, n. 139, p. 355-372, 2017. Disponível em: http://www.scielo.br/pdf/es/v38n139/1678-4626-es-38-139-00355.pdf. Acesso em: 15 nov. 2020.

PESQUISA NACIONAL POR AMOSTRA DE DOMICÍLIOS CONTÍNUA (PNAD). Rio de Janeiro: IBGE, 2015-. 2020. Disponível em: https://cidades.ibge.gov.br/brasil/rj/pesquisa/10070/64506. Acesso em: 2 dez. 2020.

RUMMERT, Sonia Maria; ALGEBAILE, Eveline; VENTURA, Jaqueline. Educação da classe trabalhadora brasileira: expressão do desenvolvimento desigual e combinado. Revista Brasileira de Educação, São Paulo, v. 18, n. 54, p. 717-738, jul./set. 2013. Disponível em: https://www.scielo.br/pdf/rbedu/v18n54/11.pdf. Acesso em: 23 dez. 2020.

VERDÉLIO, Andreia. Com 726 mil presos, Brasil tem terceira maior população carcerária do mundo. Agência Brasil, Brasília, DF, 8 dez. 2017. Disponível em: https://agenciabrasil.ebc.com.br/geral/noticia/2017-12/populacao-carceraria-do-brasil-sobe-de-622202-para-726712-pessoas. Acesso em: 23 dez. 2020

Data de submissão: 25/12/2020

Data de aceite: 22/01/2021 
